\title{
Structural Industry Modernization as a Factor of Innovative Development of a Region's Economy*
}

\author{
Eva Frizovna Khandamova \\ Marketing and Business Communications Department \\ Kuban State Technological University \\ Krasnodar, Russia \\ E-mail: ewa-h@yandex.ru
}

\author{
Aleksandr Vasilyevich Rodin \\ Local Development Organization and Planning Department \\ Kuban State University \\ Krasnodar, Russia \\ E-mail: mailteor@mail.ru
}

\author{
Mikhail Borisovich Shchepakin \\ Marketing and Business Communications Department \\ Kuban State Technological University \\ Krasnodar, Russia \\ E-mail: shchepakin@mail.ru
}

\section{Viktor Anatolyevich Gubin}

Marketing and Business Communications Department Kuban State Technological University Krasnodar, Russia E-mail: d_vag@mail.ru

\begin{abstract}
The article highlights the factors that may affect structural modernization of the industrial production sphere. Its economic substance and managerial identity are revealed. A conceptual model of managing functioning and development of a region's industrial complex in the way of the "restructuring" factor is suggested. Dominant features of structural modernization are defined. The mechanism for managing structural modernization of a region's industry is described.
\end{abstract}

Keywords-modernization-defining factors; model and mechanism for managing structural modernization of a region's industry; restructuring

\section{INTRODUCTION}

Despite a relatively high GDP growth rate, the technicaland-technological status and the scientific-and-technical level of Russia's industrial sphere continues to be fairly low against the background of the developed countries, which constrains its ability for potential-building in order to create preconditions for the substantial enhancement of economic growth rate. Achieving the assigned goal in relation to proceeding to the economic "leap" of great significance for the country can be ensured only through cardinal changes in the innovation status of various spheres and economic sectors. One of them is a region's industrial complex, which is at the forefront of the competitive battle and cannot exist without a sustainable response (including the structural response) to the challenges and threats of the globalized market environment. [1] Under these conditions, the problem of structural transformations in the economies of individual countries (and their territories) takes a new meaning and a new economic content, while drawing qualitatively-different social groups and various categories of professional workers into the process of innovative transformations. Notwithstanding the fact that structural modernization has

*Fund: This article has been produced by the authors with the support of The Russian Foundation for Basic Research in the framework of Research Project No. 19-410-230016 p_a been, for a fairly long time, an established practice of the national economic management as being an effective tool for controlling the development of various branches of the country's economy, the conceptual and substantive aspects of interpreting the economic nature of modernizing changes are subject to permanent clarification given the controversial profile of the processes, which accompany the planned and outlined (at different levels of the economy regulation and management) transformations involving the particular market partners (the state, regions, business structures of various forms of incorporation and functional belonging, social institutes and the society). The proper scientific and applied attention is lacking when it comes to the factors and priorities that, in a substantial way, determine the type, the scale and the quality of the restructuring processes operating in the particular spheres of life of the society. There are no generally-recognized approaches to managing structural modernization of a region's industry, which produces a negative impact on the effectiveness of modernizationoriented transformations.

\section{ThE FACTORS OF StRUCTURAL MODERNIZATION}

The priority factors affecting the structural modernization processes can be distinguished as follows: a) the distance between innovative transformations and the "knowledgeand information-based economy," when it comes to the practical orientation of business; b) the destruction of structural units, that are mutually-conditioned and defining the development of the production sphere, in the system of scientific and practical (research and development) support for transformation projects and programs that are being worked out; c) the imbalance between the economy and education in the business-process building system and in elaborating the directions for the restructuring changes; d) the underestimation of the influence of motivation- and communication-related factors when building behavioral models for the business and its personnel in the process of 
making decisions concerning the improvement of functioning and development of various kinds of activity; e) the disregard of escalating conflicts, controversies and disagreements in the system of relations between different participants of the marketing-communications space (in the external environment, inside the business and the local business formations); f) the discounting of the threats that spring from an inner state of the workforce and the communities, as well as not reaching agreements between the bodies of authority and the business, between the entrepreneurs and their employees, between the state, the business and the communities; g) the ease of the state impact in the areas of life of the society where the importance of the social and moral priorities is prevailing and defining the innovative and creative activity of the human-centered resource for the sake of realization of national humanistic idea of general welfare and prosperity; h) the imbalance of adaptive changes in a region's economy on key components of the transformations; i) the absence of necessary focus of the business on the economic and managerial identity of the restructuring within the limits of a specific territorial formation; $j$ ) the disregard of the impact produced by a brand as a tool for managing the marketing behavior of the economic entities against the background of structural transformations; k) the underestimation of the personnel's innovative ability in developing solutions for value chain building under the conditions of the limited availability of resources.

The priorities of structural modernization of a region's industry are determined by the strategic goals and objectives facing its economy and orienting the development of industrial sector towards satisfying the needs of the region's national economy complex, population and visitors for highquality competitive goods produced in the framework of newly-established cluster and other formations based on application of modern, efficient and environmentally-sound technologies. The modernization priorities should lie within the sphere of transformations (in business, in managing sectors and complexes, in the system of intra-corporate relations, in the internal processes of changing states and potentials of the resource components) that modify the nature, the quality and the results of work while forming the socioeconomic and moral-ethical society development vectors that are necessary for the society and the state.

\section{THE ECONOMIC SUBSTANCE AND MANAGERIAL IDENTITY OF STRUCTURAL MODERNIZATION}

Although the substantive bases of structural modernization are viewed differently by various authors, the great majority of them tend to perceive it not as a one-off event, but as a key parameter of transformations, as some kind of ideology of business operation and development. [2] The structural modernization of business is the process of adaptation of economic entities to the market reality defining demand and competition: changing of production and technological chains; the establishment of the system of integrative links between various stakeholders in the relations; the inclusion of the diversification of productive and commercial activities as a tool for managing the sustainable business development; the development of marketing-behavioral instruments for controlling the competitive position of a production enterprise; creating of new marketplaces based on a qualitatively-different informational and communicational platform; the arrangement of marketing networks in various areas of business process building; organizing of the necessary service as a condition of the targeted customer focus; the adaptation of the product range to the requirements of buyers, investors, intermediaries and other market agents; the elimination of various kinds of discords through changing the managerial processes and modulation signals emanating from the sources of different origin and level (the state, business, the population, workers, etc.). [3] [4] Within this framework, the economic substance of structural modernization is suggested to be perceived as an ability that is incidental to any business formation (agent) to the continuous growth defining the satisfaction of its internal needs for self-preservation and development that is becoming actualized through changing the structure of its interconnected potentials (technical, technological, financial, human resource, marketing, communicational, behavioral potential and others), which provide for an adequate reaction of this business formation to the external challenges, risks and threats and are fortified with relevant motives of the participants in the relations for innovative changes in the production sphere, and which are characterized by the increasing communicational permeability of the agents towards the establishment of rational relationships with various participants operating in the marketingcommunications space. These relationships should be balanced in terms of the parties' benefits and interests in orienting them towards strengthening of socio-economic dominance in the development of the society. Thus, it appears possible to state that managing structural modernization: a) by its economic nature, is a means of reacting to the outside challenges and threats allowing for self-preservation and self-development of a region's industry; b) in terms of form, displays the total set of interconnected and complementary structural transformations that modify different potentials of agents of the regional industry in the framework of the defined modernization paradigm of its development; c) in terms of content of behavioral manifestations, characterizes the uninterrupted constructive and corrective (and, under certain specific conditions, destructive) impact, as part of the specific behavioral reactions, produced by the agents on the interconnected components of a region's industry potential (see "Fig. 1"). 


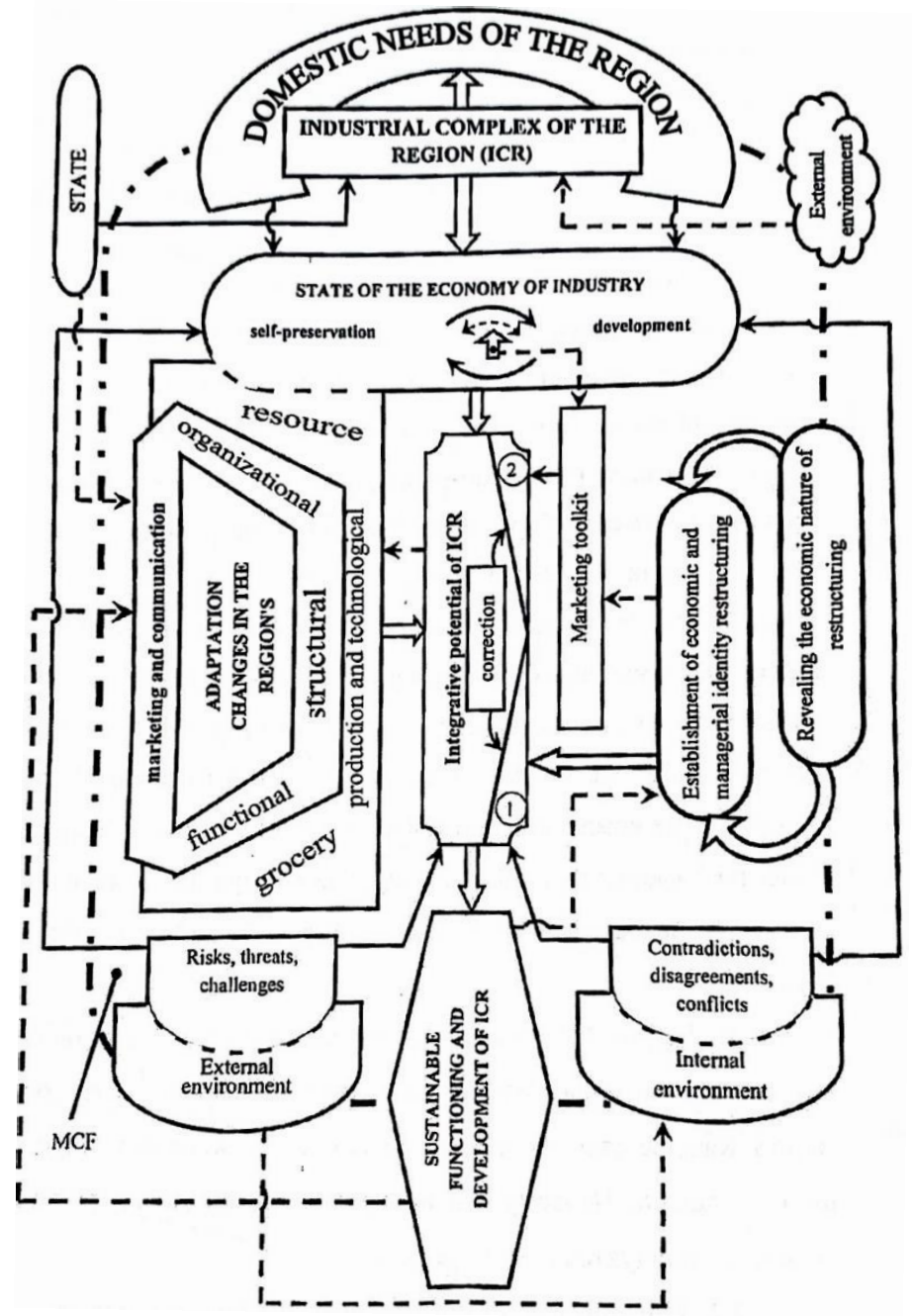

Fig. 1. A conceptual model for managing the functioning and development of the industrial complex by the factor "economic and managerial identity of restructuring".

${ }^{\text {a. }}$ Designations: $仑$ - socio-economic vector; MCF - marketing communication field, 1 - destruction; 2 - formation.

\section{The Mechanism FOR StRUCTURAL MODERNIZATION OF A REGION'S INDUSTRY}

The structural changes in the upcoming transformation programmes depend on the expression of various dominators: motivational, social and behavioral one. [5] The factors, which have the defining role and affect the process of restructuring the industrial sphere, can be characterized by the fraction of their expression (as compared to a unit (defined as 1), which is the maximum possible realization of each of them in implementation of a particular project) in the current state of the country's economy and in the current state of the market relations. We shall identify the defining factors as follows: a motivational dominant, a sociallyoriented dominant and a behavioral dominant. The specified factors can be characterized by the measure of their expression (in fractions of a unit (defined as 1) for various states of the socio-economic system (in a region or applied to a separate territory) and for different time horizons (periods) of their assessment, which are taken into consideration when forming a mechanism for managing structural modernization (see "Table I").

TABLE I. THE IMPACT OF DEFINING FACTORS ON THE STRUCTURAL MODERNIZATION PROCESS IN THE INDUSTRIAL SPHERE OF ECONOMY

\begin{tabular}{|l|l|l|l|}
\hline \multirow{2}{*}{ Factor } & \multicolumn{3}{|c|}{ Expression of impact of a factor } \\
\cline { 2 - 4 } & $\begin{array}{l}\text { In the current } \\
\text { state of the } \\
\text { socio-economic } \\
\text { system }\end{array}$ & $\begin{array}{l}\text { The needed } \\
\text { expression of } \\
\text { impact of a } \\
\text { factor }\end{array}$ & $\begin{array}{l}\text { The expected } \\
\text { expression of } \\
\text { impact of } \\
\text { factor * }\end{array}$ \\
\hline $\begin{array}{l}\text { Motivational } \\
\text { dominant }\end{array}$ & $0.28-0.29$ & $0.55-0.59$ & $0.31-0.32$ \\
\hline $\begin{array}{l}\text { Socially-oriented } \\
\text { dominant }\end{array}$ & $0.20-0.22$ & $0.43-0.45$ & $0.25-0.26$ \\
\hline Behavioral dominant & $0.16-0.18$ & $0.72-0.75$ & $0.33-0.35$ \\
\hline Other factors & $0.59-0.61$ & $0.35-0.36$ & $0.65-0.67$ \\
\hline
\end{tabular}


The mechanism for structural modernization is a set of states and processes directed at changing the interior arrangement and the system of interrelations between its elements and the components of a region's industry potential that make it possible to ensure the structural sustainability of the regional industry from the perspective of solving the strategic tasks of its development. This mechanism, in an algorithmic context, consists of: a) the determination of quantitative and qualitative parameters of a region's industry potential required for solving the strategic tasks facing the industry; b) the assessment of quantitative and qualitative parameters of the potential possessed by the agents of a region's industrial complex; c) the evaluation of the degree of the structural conformity of a region's industry potential to the set strategic tasks; d) the definition of priority zones of structural modernization and identification of its key link invested with the properties of a regional marketing implant; e) the development and implementation of programmes for structural modernization of a region's industry ensuring the achievement of the required parameters of its potential for strengthening the trend to economic growth; f) monitoring and the adjustment of programmes for structural modernization of a region's industry with regard to the changes of potentials by economic operators; g) reaching the desired (specified) parameters of a region's industry potential; h) solving strategic tasks for the development of a region's industry based on the rationalized use of the set of resources involved in modernization-related transformations.

When constructing a mechanism intended to manage the restructuring of a region's industrial complex, it is necessary to identify and designate the regional marketing implant that should be the basis for the arrangement of expanding interrelations between the cooperation-seeking market actors and the formation of the resource flows that can stabilize the restructuring cycles of the economic entities. The latter should be motivated towards cooperation and solving controversies, discords and conflicts of various kinds in order to activate their innovative ability in building innovation chains for product development and manufacturing, in the framework of which changes of the entities' different potentials are to be formed. While creating a unified motivational field of operators in the industrial sphere (the industrial complex) that "drags" into itself the market agents performing the associated types of activities, the attention of managerial structures at various levels should be focused marketing-behavioral factor when it comes to elaboration of decisions for creation of innovation chains with the purpose of production of particular goods. It produces its impact most clearly when establishing communications inside the business, between the business and the authorities, between the participants in the relations and other representatives of the market space as concerns solvability or insolvability of the existing disagreements between them. [6] The "circle" of different kinds of controversies defines the content, the scale and the quality level of the constructed restructuring cycle in every enterprise of the industrial complex, because it is the source of those possibilities that may be used for shifting the entities' potential in the right direction when reaching consensus between opposing parties. The limited availability of resources when elaborating restructuring programmes forces the business to integrate a resource decompensator, which is formed by the agents from the external environment and the associated spheres of activity, into realization of the envisaged solutions. Within the limits of the unified motivational field of economic entities oriented towards the rational use of resources, the marketing-behavioral factor changes its impact under the influence of socio-economic vector of a region's economy development. The latter requires to be clearly identified, because it affects the pattern of the employees' marketing or other behavior, which is revealed in their attitude toward the professional activity and the policies of the business owners, as well as in their strivings to realize their innovative abilities for the sake of the business, their economic status and moral-ethical situation in the entrepreneurial structure. [7]

The mechanism for managing the structural modernization of a region's industry (see "Fig. 2") in a marketing-component context combines in itself changing the constituent parts of its potential, namely: a) personnel potential (labor potential), b) technological potential; c) production and technical potential; d) resource potential (material, primary goods, energy, etc.); e) marketing potential; f) organizational and managerial potential; g) behavioral potential; h) communications potential; i) motivational potential. The total set of the specified potentials forms an integral effectiveness indicator of the structural modernization. Its mismatching the required level (with a breakdown into constituent parts) compels the economic entities to work out measures for changing potentials, while involving for this purpose the cooperationseeking market agents possessing the specific kinds of resources for the establishment of a rational restructuring cycle by each of these entities. [8]

On content, the mechanism for managing the structural modernization of a region's industry is characterized by constructive, corrective and destructive lines of measures implemented as part of it and providing for solving the existing controversies and conflicts. 


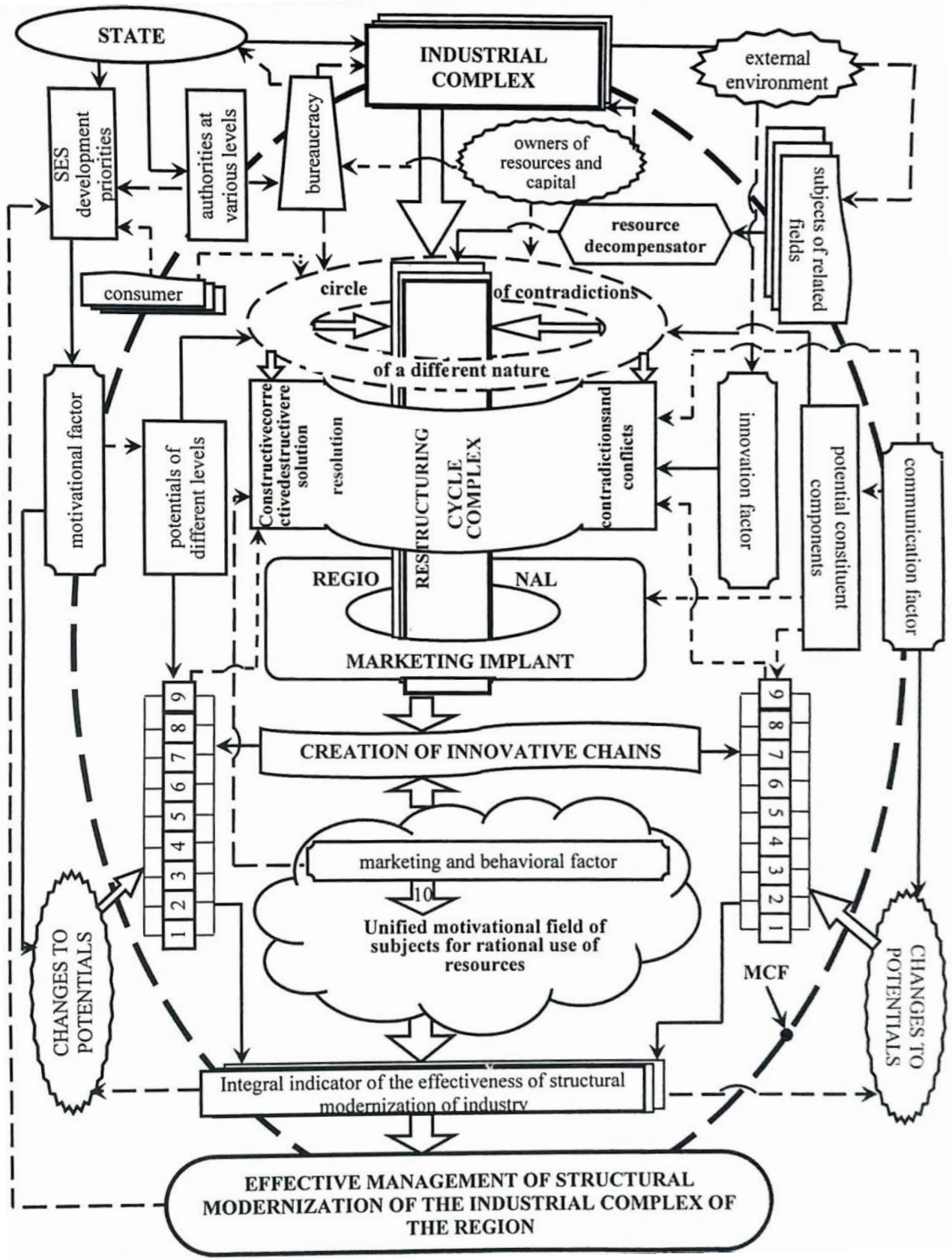

Fig. 2. Mechanism for managing the structural modernization of industry in the region (marketing component context).

Designations of potentials: 1 - personnel (labor); 2 - technological; 3 - production and technical; 4 - resource (material, raw, energy, etc.); 5 - marketing; 6 - organizational and managerial; 7 behavioral; 8 - communication; 9 - motivational; 10 - socio-economic vector of the development of the economy of a region (country).

The mechanism for constructive modernization provides for a series of measures oriented towards changing potentials of various components of a region's industry through the creation of principally-new production enterprises, the formation of innovative value chains (including those based on a regional marketing implant), the establishment of new business units or their associations (clusters, sub-clusters), the activity of which ensures the achievement of the strategic regional development goals.

The mechanism for corrective modernization calls for the measures allowing for quantitative changes in various potentials of a region's industry (and from the perspective of the economic entities as well) by means of redeployment of the resources and capacities possessed by the entities in order to reach the balanced internal state in the system of relationships that are being built between the elements (components) of the industrial complex and beyond, as well as to maintain the rational interrelations between the structural subdivisions of the existing production enterprises, operating business units or their associations (clusters, subclusters) for the sake of enhancement of the competitiveness of a region's industrial complex and solving the tasks of ensuring the economic growth of a local territorial formation. 
The mechanism for destructive modernization provides for the measures allowing for changing a region's industry potential by means of complete or partial destruction of the existing and industry-shaping production enterprises, as well as by closing-down the economic entities (business units) and their associations (clusters, sub-clusters), the activity of which does not provide for or contribute to achieving the strategic goals of regional development against the background of real resource coverage. The destructive modernization is always associated with elimination of inefficient value chains involving destruction of the existing industrial potential and rejection of innovative transformations based on a qualitatively-new (or progressive) technological platform. [9]

The modernization-related transformations in the industrial sphere of economy in a region should be geared towards ensuring a stable balance of the constituent economic entities (or complexes, or business units, or their associations), directed at the formation of such position of this sphere in the market space, in which the agents, taken off the state of stable functioning and development due to escalation or aggravation of discords of different nature, scale and focus occurring inside or outside the business, make efforts to take up competitive positions in the changing market.

\section{CONCLUSION}

The conceptual aspect of managing the industry restructuring in a region lies in the fact that the processes and phenomena accompanying changes in the structural modernization of the industrial sphere should allow for the impact produced by the factors that determine these transformations (motivational, communication-related, behavioral, innovation-related, organizational and managerial ones, etc.), which are linked to the internal state of the participants in the relations. The nature and the substance of internal state of the entrepreneurial sphere depend on the degree of solvability of controversies, discords and conflicts, as well as on the abilities of a business (and its personnel) to confront the fluctuating threats and risks against the background of turbulent challenges posed by external environment. Changes in internal state of a business in the course of introducing modernization- and restructuring-related transformations form the structural sustainability of economic entities, which expresses itself through weakening of unsolvable motivation and resourcebased controversies, conflicts and disagreements and contributes to strengthening of the right balance of interests held by the business operators in the marketing communications field, in the framework of which innovative projects and business development programmes can be implemented within the confines of certain territories (regions).

At the core of the model for managing structural modernization of industry in a region lies the understanding of economic substance of restructuring as being its ability for self-preservation and development, that are continuous and defining the satisfaction of its internal needs, by means of changing the structure of interconnected potentials (technical, technological, financial, human resource-related, communication-related, behavioral ones, etc.). The model makes it possible to ensure an adequate reaction from the participants of cooperation to external challenges, risks and threats, as well as to the internal state of the workforce (in terms of changing parameters of controversies, discords and conflicts that are being solved to a particular extent (in a particular way).

The mechanism for structural modernization of a region's industry should be viewed: a) in algorithmic context (from the perspective of building a logical sequence of modernization-related measures ensuring its structural sustainability); b) in componential context (from the perspective of structuring the available potentials reflecting various facets of modernization-related measures and transformations); c) in substantive context (from the perspective of establishing the right focus of modernizationrelated changes). They may form a complete understanding of the total set of processes and phenomena that take place as part of modernization-related transformations aimed at changing the internal state of the agents, at shifting the structural and organizational proportions in a business, at modifying the system of interrelations between the components of a region's industry potential. The mechanism for structural modernization of a region's industry allows for ensuring its structural sustainability with regard to solving the strategic tasks of development and creating preconditions for sustained growth in the economy of a local territorial formation.

\section{REFERENCES}

[1] Gubin V.A., Shchepakin M.B., Gubin G.V. Regional economy restructuring management: approaches, priorities and mechanisms. Krasnodar: Publishing House - Yug, 2014. - 166 p.

[2] Mironov V.V, Konovalova L.D. On interdependence of structural changes and the economic growth in the world economy and in Russia. Voprosy Ekonomiki ("Economic issues"). 2019; (1):5478. https://doi.org/10.32609/0042-8736-2019-1-54-78

[3] Chernobrovkina N.I. Economic identity as a form of self-definition and self-positioning of a regional community// Gumanitariy Yuga Rossii ("Southern Russia humanitarian"). - 2015. - No. 1(8). - pp. 134-141.

[4] Varlamov A.S. Organizational and economic essence of restructuring// "The bulletin of South Ural State University." Series: Economy and management. - 2008. - Issue 5. - pp. 3-10.

[5] Hammer M., Champy J. Reengineering the Corporation: A Manifesto for Business Revolution; translated from English. - SPb.: Publishing house of Saint-Petersburg University, 1997. - 332 p.

[6] Rodin A.V. Institutional conditions for intersectoral collaboration in ensuring sustainable development of territories//Modern Economy Success. International scientific journal. - 2018. - No. 4. - pp. 15-20.

[7] Goldberg I., Watkins A. Enterprise restructuring// Investments in Russia. - 2000. - No. 6. - pp. 13-20.

[8] Shchepakin M.B., Gubin V.A., Khandamova E.F. Conceptual aspects of managing a region's industry restructuring// Leadership and management. - 2019. - Vol. 6. - No.3. - pp. 257-278.

[9] Shchepakin M.B., Gubin V.A. Industry restructuring priorities in Krasnodar Krai and the factors defining its effectiveness// "Economic relations." - 2019. - Vol. 9. - No. 3. -pp. 1711-1734. 